\title{
Nursing faculty teaching a module in clinical skills to medical students: a Lebanese experience
}

This article was published in the following Dove Press journal:

Advances in Medical Education and Practice

13 November 2014

Number of times this article has been viewed

\section{Bahia Abdallah' \\ Jihad Irani² \\ Silva Dakessian Sailian' \\ Vicky George Gebran' \\ Ursula Rizk' \\ 'Nursing Program at the Faculty of Health Sciences, University of Balamand, ${ }^{2}$ Faculty of Medicine and Medical Sciences, University of Balamand, Beirut, Lebanon}

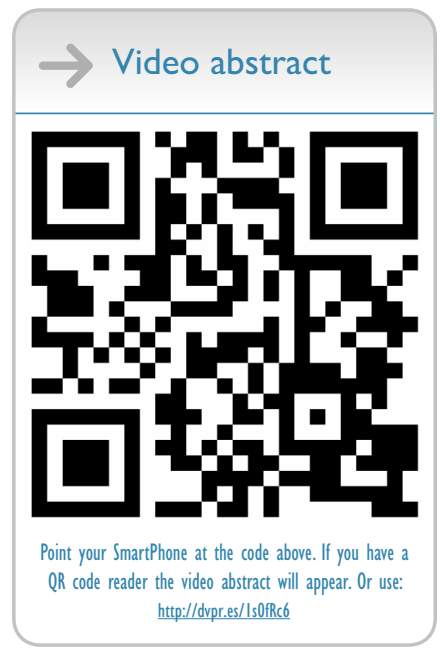

Correspondence: Bahia Abdallah University of Balamand, Faculty of Health Sciences, Youssef Sursok Street, St George Health Complex, PO Box 166378 Ashrafieh, Beirut II 00-2807, Lebanon Tel $+96 \mid$ | 56678 |

Fax+96| | 566780

Email bahia.abdallah@balamand.edu.lb
Abstract: Nursing faculty teaching medical students a module in clinical skills is a relatively new trend. Collaboration in education among medical and nursing professions can improve students' performance in clinical skills and consequently positively impact the quality of care delivery. In 2011, the Faculty of Medicine in collaboration with the Faculty of Health Sciences at the University of Balamand, Beirut, Lebanon, launched a module in clinical skills as part of clinical skills teaching to first-year medical students. The module is prepared and delivered by nursing faculty in a laboratory setting. It consists of informative lectures as well as hands-on clinical practice. The clinical competencies taught are hand-washing, medication administration, intravenous initiation and removal, and nasogastric tube insertion and removal. Around sixty-five medical students attend this module every year. A Likert scale-based questionnaire is used to evaluate their experience. Medical students agree that the module provides adequate opportunities to enhance clinical skills and knowledge and favor cross-professional education between nursing and medical disciplines. Most of the respondents report that this experience prepares them better for clinical rotations while increasing their confidence and decreasing anxiety level. Medical students highly appreciate the nursing faculties' expertise and perceive them as knowledgeable and resourceful. Nursing faculty participating in medical students' skills teaching is well perceived, has a positive impact, and shows nurses are proficient teachers to medical students. Cross professional education is an attractive model when it comes to teaching clinical skills in medical school.

Keywords: cross-professional education, CPE, clinical skills, medical education, nursing faculty, clinical performance

\section{Introduction}

For the last two decades, there have been concerns about the adequacy of clinical skills education of junior doctors in terms of content and competency. These concerns were mainly around the unpreparedness and high anxiety of medical students in their early clinical practice. ${ }^{1-4}$ Therefore, many innovative learning interventions and interprofessional education (IPE) initiatives, specifically nursing faculty teaching medical students, have been utilized for better student preparedness in various laboratory and clinical clerkships in the US and Europe..$^{5-11}$ Nursing faculty teaching medical students clinical skills is a relatively new trend in the past decade. This approach in education is believed to improve the clinical competencies of medical students by increasing their confidence in clinical performance. ${ }^{5}$ This collaboration in education among the medical and nursing professions improves students' perceptions of nurses as expert teachers, adds to the value of the learning experience, and consequently impacts the quality of 
care delivery. ${ }^{5,12}$ For these reasons, IPE and cross-professional education (CPE) have gained attention in academia and have been practiced with good reverberation in different medical schools and faculties worldwide. .,7 $^{6}$

CPE encourages faculty members of different specialties and professions to teach students of the same major sharing their unique expertise (eg, nursing faculty teaching medical students). Likewise, IPE allows students of different majors, for instance medical and nursing students, to share the same classroom and learn together. "Inter-professional Education occurs when two or more professions learn with, from and about each other to improve collaboration and the quality of care". 13

IPE and CPE initiatives were launched in the early 1960s in the UK and the US as seminars or workshops, mostly in nursing, social work, medicine, and other allied health specialties. ${ }^{14}$ Before the year 2000 , more than $50 \%$ of the institutions of higher education in the UK had some kind of "shared learning" courses whether at the undergraduate or post-graduated levels.

Several descriptive quantitative and qualitative studies in the UK, Australia, and Canada reported the effect of nursing faculty teaching medical students. They described increased confidence levels of medical students in performing clinical skills, improved proficiency, more collaboration between professions, and better understanding of each other's roles and responsibilities. ${ }^{5-7,11,12,15}$

Within the Lebanese context, and to the authors' knowledge, there is no published research about collaborative education between the nursing faculty and medical students. However, the only collaboration is at one medical school in Beirut, which follows a 7-year program post-high school, where selected nurses take charge of educating junior medical students about infection control standards and other basic clinical skills like hand-washing and intravenous (IV) initiation (Rita Slim, MD, personal communication, Gastroenterology Unit, Hôtel-Dieu de France University Hospital, July, 2012). Although specific endeavors have been made to enrich medical education, there are still gaps in medical curricula across Lebanese medical schools in terms of medical students mastering clinical skills.

From this perspective, CPE was initiated at a medical school where nursing faculty were responsible for teaching medical students a module in clinical skills in a laboratory setting. This study, which is the first of its kind in Lebanon, aims to describe the experience of nursing faculty teaching a module in clinical skills to medical students and to evaluate the effect of this experience on their confidence and anxiety level. In addition, it assesses the medical students' perception towards CPE as a novice teaching strategy.

\section{Methods}

\section{Setting}

The University of Balamand is a relatively new Lebanese university, with different faculties, including the Faculty of Health Sciences (launched in 1995) and the Faculty of Medicine (launched in 2001). The nursing program, operating under the Faculty of Health Sciences, offers a Bachelor of Sciences degree after 3 years of education, including an internship period. The Faculty of Medicine follows the American model, with 4 years of medical education after completing a Bachelor of Sciences/Pre-Med degree. The first 2 years are non-clinical, and the last 2 years consist of a succession of clinical clerkships and electives. Students' initiation to history taking and physical examination skills starts in MED-I, and extends into MED-II within the framework of "Clinical Skills" courses I and II, respectively. During these courses, they are assigned to minirotations at the affiliated hospital for a period of 4 weeks.

In 2010, a new activity was introduced to MED-II students embedded within their Clinical Skills-II course, which takes place directly before their third year. They had to spend a morning with a registered nurse, as part of their Clinical Skills-II mini-rotations.

In 2011, and in order to better prepare students for their "clinical rotation," MED-I students were introduced to a "Module in Clinical Skills" in a hands-on perspective in the Nursing Training Laboratory, within the context of their Clinical Skills-I course. This Module was prepared and delivered by nursing faculty from the Faculty of Health Sciences. The selected faculty were experienced Master's degree holders and full-time lecturers of such skills incorporated in the Fundamentals in Nursing Practice course given to first-year nursing students. The module consisted of informative lectures as well as hands-on clinical practice. The module content and framework were developed after reviewing the literature around this topic. Several meetings between the medical school course coordinator and the nursing program course coordinator were conducted to finalize the nursing skills content and methods of delivery. The four clinical competencies agreed upon were hand-washing, medication administration, IV initiation and removal, and nasogastric (NG) tube insertion and removal. Effective communication, nurturing patients, empowering and engaging family members were all topics addressed by faculty throughout the covered procedures.

The three lectures were posted online via the "MOODLE" intranet site for students' use with suggested readings. 
The lectures covered the following topics:

1. The principles of universal safety precautions, handwashing technique, administering medications, aseptic and safe techniques in preparing, handling, and discarding used materials.

2. IV catheter initiations, indications, IV insertion technique, proper IV insertion sites, preparation of equipment, IV drip calculation, potential complications, and IV catheter removal.

3. NG tube insertion, indications, contraindications, preparation of equipment, insertion techniques, NG feeding, NG removal, and potential complications.

The lectures were delivered to all students in a common lecture hall by the nursing program course coordinator followed by nursing laboratory skills practice hours supervised by nursing faculty.

\section{Participants}

A total of 132 medical students attended the Nursing Clinical Skills module between 2011 and 2012. All students attended the didactic lectures; students were divided into small groups of six to seven for the laboratory sessions. Each group "rotated" in the nursing lab 1 day per week for 3 hours over 2 weeks, while classmates were fulfilling their own rotations on the different units at the hospital. During the sessions, a 2:1 or 3:1 medical student to nursing faculty ratio was respected to be safe and as a starting module. Medical students were also assisted by second-year nursing students who completed the Fundamentals of Nursing course in preparation of materials for the procedure. It is worth noting that this allowed for positive interaction between nursing and medical students.

\section{Laboratory skills practice}

Every student attended a total of two laboratory skills sessions, 3 hours each (hand washing, intramuscular/subcutaneous/ intradermal injection, IV insertion, and NG tube insertion) distributed over 2 weeks as a requirement to complete the module. The information covered in the three lectures was reinforced during the laboratory skills sessions. All the sessions were conducted in the nursing training laboratory at the Faculty of Health Sciences. Nursing faculty started each laboratory session by conducting a role-play activity with emphasis on proper and ethical communication skills, whereby patient's rights, patient identification, privacy, and dignity are emphasized and respected. Role modeling was performed on manikins by nursing faculty, where the caring nursing approach integral to nursing practice is emphasized while maintaining safety measures towards the patient and oneself throughout the procedures. The role-play was followed by individual student applications, ensuring that all necessary steps were maintained and performed. Hand washing was practiced during each session before and after the clinical procedure. Injections were primarily practiced on manikins and followed by safe exercises on peers in the group. The IV and the NG insertion/removal procedures were only practiced on manikins.

\section{Evaluation strategy}

The evaluation form was adapted from the Elms and Chumley study. ${ }^{6}$ It assessed the content of the module, nursing faculty performance, perception of students towards CPE and collaboration, and effect on students' confidence and anxiety level in performing clinical skills. It consisted of 27 questions using a five-point Likert scale. Fourteen questions specifically assessed the students' general evaluation of the experience with a scale ranging from strongly agree to strongly disagree. Six questions assessed the students' evaluation of nursing faculty as lecturer and/or preceptor in the laboratory sessions. Eight questions on a Likert scale evaluated the students' performance and confidence level. The confidence level was particularly assessed on each skill with a scale ranging from outstanding to poor. The questionnaire ended by one open-ended question asking about student suggestions and remarks on the strengths and weaknesses of the experience. The questionnaire was pilot tested on seven students, and some minor amendments were introduced according to their feedback. Students completed the evaluation form at the end of the final session of the course.

\section{Statistical analysis}

Classical descriptive statistics were used to analyze results. Quantitative data was summarized using means and standard deviations; qualitative data was summarized using counts and proportions. In the analysis, the categories "strongly agree" and "agree" were combined versus the other categories. SPSS version 20 was used for computations.

\section{Results}

A total of 126 students returned the questionnaire (response rate $96 \%$ ), 63 students from each year. Male students represent $57 \%$ of the participants (61\% of the 2011 group, 54\% of the 2012 group).

The overall evaluation of students' experience was favorable (Table 1). In fact, most of the responses came under "strongly agree" and "agree," with few responses disagreeing with the experience. Students judged the experience to be in line with the objectives of their Clinical Skills course. It helped their communication skills, and the material (disposables, 
Table I General evaluation of the experience

\begin{tabular}{|c|c|c|c|}
\hline & $\begin{array}{l}\text { Average } \\
\text { score }\end{array}$ & $\begin{array}{l}\text { Strongly disagree, } \\
\text { disagree, and neutral (\%) }\end{array}$ & $\begin{array}{l}\text { Strongly agree } \\
\text { and agree (\%) }\end{array}$ \\
\hline Agreed with the objectives of the Clinical Skills course & 4.8 & 0 & $125(100)$ \\
\hline Provided adequate opportunities to enhance clinical skills and knowledge & 4.8 & 0 & $126(100)$ \\
\hline Provided adequate opportunities to strengthen communication skills & 4.5 & $3(2)$ & $123(98)$ \\
\hline Material used was adequate & 4.7 & 0 & $125(100)$ \\
\hline Long enough to meet personal learning objectives & 4.4 & $10(8)$ & $116(92)$ \\
\hline Helped integrate knowledge from other courses & 4.3 & $10(8)$ & $116(92)$ \\
\hline $\begin{array}{l}\text { Cross professional education and collaboration between nursing and } \\
\text { medical disciplines is an acceptable and effective strategy for teaching } \\
\text { specific skills to medical students }\end{array}$ & 4.8 & 0 & $126(100)$ \\
\hline $\begin{array}{l}\text { Hands on learning prepare medical students for clinical rotations while } \\
\text { increasing confidence }\end{array}$ & 4.7 & 0 & $126(100)$ \\
\hline $\begin{array}{l}\text { Hands on learning prepare medical students for clinical rotations while } \\
\text { decreasing anxiety }\end{array}$ & 4.8 & 0 & $126(100)$ \\
\hline $\begin{array}{l}\text { Lab provided an opportunity for real collaboration between the different } \\
\text { disciplines and exposed medical students to nurses as experts }\end{array}$ & 4.7 & $I(I)$ & 125 (99) \\
\hline I learned general principles that will enhance my ability to care for patients & 4.8 & $I(I)$ & $125(99)$ \\
\hline Sessions met my immediate learning needs for the laboratory skills & 4.7 & $2(2)$ & $124(98)$ \\
\hline Sessions' content presented at appropriate level & 4.8 & $I(I)$ & $125(99)$ \\
\hline Sessions well organized and timely & 4.7 & $2(2)$ & $60(97)$ \\
\hline
\end{tabular}

supplies, and manikins) used was adequate. Eight percent of students perceived the duration not to be long enough to meet objectives; they asked for longer time for learning clinical skills. The same number of students could not identify how those skills integrate knowledge from other courses.

It is worth mentioning that all respondents (100\%) favored CPE and collaboration between nursing and medical disciplines, and evaluated those sessions to be helpful in taking care of their patients.

As for nursing faculty evaluation (Table 2), all of the students $(100 \%)$ highly praised the availability, support, responsiveness to questions and concerns, and knowledge of the nursing faculty while providing these sessions.

Table 3 depicts students' opinions regarding the nursing skill method of delivery, and most of the responses fell between "good" and "outstanding." Table 3 also shows medical students' confidence in performing the different clinical skills taught during the sessions. Students felt that they gained good confidence in the learnt skills, especially in injection (94\%) and hand washing (92\%), but less in IV push and microdrip (80\%).

Finally, students' responses to the open-ended question about what they would do differently or change within this module came under one of the following themes: 1) no changes needed "everything is just perfect," 2) need for more practice time in the nursing laboratory, including nursing rotations at the hospital after each session, and 3) need to practice on real patients. Few students (8\%) asked for more time to learn the clinical skills, and others preferred to practice the skills on living human volunteers. However, the physical setting and the time restriction of the faculty could not adjust for this.

\section{Discussion}

The data collected suggest that clinical skills laboratory experience had a positive effect on medical students in general.

Table 2 Evaluation of nursing faculty

\begin{tabular}{|c|c|c|c|}
\hline & $\begin{array}{l}\text { Average } \\
\text { score }\end{array}$ & $\begin{array}{l}\text { Strongly disagree, } \\
\text { disagree, and neutral (\%) }\end{array}$ & $\begin{array}{l}\text { Strongly agree } \\
\text { and agree (\%) }\end{array}$ \\
\hline Provided adequate orientation to clinical skills & 4.8 & 0 & $126(100)$ \\
\hline Available and supportive of learning needs & 4.8 & 0 & $126(100)$ \\
\hline $\begin{array}{l}\text { Collaborated with me effectively in evaluating } \\
\text { my learning needs and progress }\end{array}$ & 4.8 & $\mathrm{I}(\mathrm{I})$ & $124(99)$ \\
\hline Lecturer appeared prepared & 4.9 & $2(2)$ & $124(98)$ \\
\hline Lecturer responsive to questions and concerns & 4.8 & 0 & $126(100)$ \\
\hline Lecturer knowledgeable and resourceful & 4.9 & 0 & $126(100)$ \\
\hline
\end{tabular}


Table 3 Clinical skills evaluation on performance and confidence

\begin{tabular}{|c|c|c|c|c|c|}
\hline & $\begin{array}{l}\text { Average } \\
\text { score (I4) }\end{array}$ & Poor & $\begin{array}{l}\text { Fair } \\
\text { (\%) }\end{array}$ & $\begin{array}{l}\text { Good } \\
\text { (\%) }\end{array}$ & $\begin{array}{l}\text { Outstanding } \\
\text { (\%) }\end{array}$ \\
\hline Hand-washing & 3.6 & 0 & $2(2)$ & $45(36)$ & $77(62)$ \\
\hline IM injection & 3.8 & 0 & 0 & $23(18)$ & $102(82)$ \\
\hline SC injection & 3.8 & 0 & 0 & $23(18)$ & $102(82)$ \\
\hline ID injection & 3.8 & 0 & 0 & $22(18)$ & $103(82)$ \\
\hline $\begin{array}{l}\text { NGT insertion } \\
\text { and removal }\end{array}$ & 3.8 & 0 & $I(I)$ & $28(22)$ & $97(77)$ \\
\hline $\begin{array}{l}\text { IV insertion } \\
\text { and removal }\end{array}$ & 3.8 & 0 & $2(2)$ & $27(21)$ & $97(77)$ \\
\hline IV push & 3.7 & 0 & $I(I)$ & $36(29)$ & 89 (7I) \\
\hline Microdrip & 3.7 & 0 & $\mathrm{I}(\mathrm{I})$ & $39(31)$ & $85(68)$ \\
\hline & \multicolumn{5}{|c|}{ Acquiring confidence in [yes answers (\%)] } \\
\hline Hand-washing & II 6 (92) & & & & \\
\hline Injections & $119(94)$ & & & & \\
\hline NGT & II 3 (90) & & & & \\
\hline $\begin{array}{l}\text { IV insertion/ } \\
\text { removal }\end{array}$ & II 3 (90) & & & & \\
\hline $\begin{array}{l}\text { IV push and } \\
\text { microdrip }\end{array}$ & I0I (80) & & & & \\
\hline
\end{tabular}

Abbreviations: ID, intradermal; IM, intramuscular; IV, intravenous; NGT, nasogastric tube; SC, subcutaneous.

All the respondents $(100 \%)$ stated that the course provided adequate opportunities to enhance clinical skills and knowledge in addition to strengthening communication skills. These findings are in accordance with Elms and Chumley, ${ }^{6}$ where medical students rated the nursing laboratory module as outstanding or good. This was evident in the respondents' $(100 \%)$ reporting in the questionnaire that hands-on learning prepared them for clinical rotations while increasing their confidence. These findings are also consistent with the results revealed by Tucker et $\mathrm{al}^{5}$ and Elms and Chumley. ${ }^{6}$ The confidence was highest in intramuscular, subcutaneous, and intradermal injections (94\%) but less in IV push and microdrip (80\%). It is worth mentioning that medical students will be applying such clinical skills throughout their medical education years, in clinical rotations, and their practice afterward.

Concerning nursing faculty evaluation, the medical students highly appreciated the nursing faculties' expertise and preparedness, perceiving them as knowledgeable and resourceful educators, teachers, mentors, and effective members of patient health care teams. These findings were congruent with the conclusions of the studies by Elms and Chumley $^{3}$ and Bradley et $\mathrm{al},{ }^{12}$ where the nurse is perceived as a valuable clinical instructor in preparing medical students for their early clinical rotation. However, the perception of medical students in the Rudland and Mires ${ }^{15}$ study was slightly different towards the shared learning. They reported that nurses were more caring than doctors in their approach but have lower academic ability and competence, and lower status in society. Therefore, introducing CPE by nursing faculty to become an integral part of the medical curriculum will contribute to upgrading the nurses' image and profession.

In this study, medical students (99\%) reported that the clinical skills module provided an opportunity for real collaboration between the nursing profession and medicine, highlighting the expertise of nurses. This is valuable observation from Lebanese medical students in a context where the nursing profession has not been always fully appreciated. ${ }^{16,17}$ The concept of increased inter-professional collaboration was discussed in the literature as an outcome of CPE by Elms and Chumley, ${ }^{6}$ Tucker et al, ${ }^{5}$ Ker et al, ${ }^{7}$ Bradley et al, ${ }^{12}$ and Kramer and Schmalenberg. ${ }^{18}$ The latter study also reported that the collaborative and collegial nurse-physician relationship translates into extended nurse contact with the patient and consequently better quality care.

This unique Lebanese CPE experience was directed in a single institution; therefore, to attest its validity, repeated experiences are needed in other universities. In addition, the long-term impact of this intervention remains to be assessed whether it is on quality of patient care, nurse-physician relationship, medical students' clinical performance, multidisciplinary collaboration, and teamwork.

We hope that this collaboration will reflect positively on nurse-physician relationship, enhancing communication and mutual respect for each other's responsibilities and knowledge.

\section{Strengths and limitations of the study}

The response rate of medical students was high. The feedback was directly collected after the delivery of the course, and the course was done in the same place for two consecutive years. However, it is worth noting that this was a 2-year experience carried out in only one university with medical students and not part of an integrated CPE plan applied throughout the medical curriculum. We do not know the long-term implication of the course. It is assumed that the systematic CPE approach would yield long-term outcomes. However, findings might not be reproduced in other settings. There is a need for wider application in different Lebanese universities to capture a larger sample size and in different settings, with long-term follow-up and outcomes-assessment measures.

The study design was a simple one; it would have been more proper to use a pre-post design study to measure confidence and anxiety level of medical students; however, due to time inconvenience, only a post-study design was utilized for this objective. 


\section{Conclusion}

CPE is a new, promising approach that could respond to medical students' needs. With this unique experience of nurseled laboratory basic skills teaching, it is expected to have improved competencies of medical students in clinical skills. Additional studies are needed to better understand the longterm impact of incorporating nurse-led laboratory teaching in the medical curriculum and its significance in the medical education, and consequently, in the delivery of patient care. It would be of interest to specifically study the effect of nurse-led teachings on nurses' self-esteem, nurse-physician collegiality, and long-term effect on nurse turnover and recruitment. Such studies are vital because they highlight the unique role of the nursing profession in medical education, and thus are of no less importance than other professions in the health care system. This experience in a Lebanese university reveals that CPE has a positive effect on collaboration and nurtures mutual dignity among different disciplines. Hence, similar experiences are encouraged in other disciplines as well.

\section{Acknowledgments}

We would like to acknowledge Dr Camille Nassar and Dr Nadim Karam, Deans of the Faculty of Medicine and the Faculty of Health Sciences at the University of Balamand, respectively, for their continuous encouragement of IPE and CPE.

\section{Ethical approval}

This work got the clearance from the Ethical Committee of Saint George Hospital University Medical Center, which is affiliated with the University of Balamand, Lebanon.

\section{Disclosure}

The authors report no conflicts of interest in this work.

\section{References}

1. Corbett, E.C., and Michael Whitcomb. "The AAMC project on the clinical education of medical students: clinical skills education." Washington, DC: Association of American Medical Colleges (2004).
2. Kalaca S, Sarikaya O, Keklik D, Gulpinar MA. What do we know about the anxieties of new clinical students? Med Educ. 2003;37:390.

3. Wood FD. Evaluating the outcomes of undergraduate medical education. Med Educ. 2003;37:580-581.

4. Matheson C, Matheson D. How well prepared are medical students for their first year as doctors? The views of consultants and specialist registrars in two teaching hospitals. Postgrad Med J. 2009;85: 582-589.

5. Tucker k, Wakefield A, Boggis C, Lawson M, Roberts T, Gooch J. Learning together: clinical skills teaching for medical and nursing students. Med Educ. 2003;37:630-637.

6. Elms SA, Chumley H. Nursing faculty teaching basic skills to medical students. Med Teach. 2006;28(4):341-344.

7. Ker J, Mole L, Bradley P. Early introduction to interprofessional learning: a simulated ward environment. Med Educ. 2003;37:248-255.

8. Remmen R, Scherpbier A, Vleuten C, et al. Effectiveness of basic clinical skills training programs: a cross-sectional comparison of four medical schools. Med Educ. 2001;35:121-128.

9. Berman N, Fall LH, Smith S, et al. Integration strategies for using virtual patients in clinical clerkships. Acad Med. 2009;84: 942-949.

10. Wakefield A, Cooke S, Boggis C. Learning together: use of simulated patients with nursing and medical students for breaking bad news. Int J Palliat Nurs. 2003;9(1):32-38.

11. Smith P, Cotton P, O'Neil A. 'Can you take a student this morning?' Maximizing effective teaching by practice nurses. Med Educ. 2009;43(5):426-433.

12. Bradley P, Bond V, Bradley P. A questionnaire survey of students' perceptions of nurse tutor teaching in a clinical skills learning program. Med Teach. 2006;28(1):49-52.

13. Sills M, Helme M, Skizas N. Pathways for interprofessional learning and teaching in higher education. Probl Hig Epidemiol. 2006; 87(4):289-299.

14. Barr H. Interprofessional Education in the United Kingdom: Some Historical Perspectives 1966-1996. 1996. Available from: http://www. caipe.org.uk/silo/files/cipw-historical-perspectives.pdf. Accessed May 10, 2013.

15. Rudland JR, Mires GJ. Characteristics of doctors and nurses as perceived by students entering medical school: implications for shared teaching. Med Educ. 2005;39:448-455.

16. El-Jardali F, Dumit N, Jamal D, Mouro G. Migration of Lebanese nurses: a questionnaire survey and secondary data analysis. Int J Nurs Stud. 2008;45(10):1490-1500.

17. Dhumieres M. Nurses' order looks to promote profession as shortage looms. The Daily Star. 2011 May 09. Available from: http:// www.dailystar.com.lb/News/Lebanon-News/2011/May-09/138133nurses-order-looks-to-promote-profession-as-shortage-looms. ashx\#ixzz30YSxHOI7. Accessed August 14, 2014.

18. Kramer M, Schmalenberg C. Securing "good" nurse/physician relationships. Nurs Manage. 2003;34:34-38.
Advances in Medical Education and Practice

\section{Publish your work in this journal}

Advances in Medical Education and Practice is an international, peerreviewed, open access journal that aims to present and publish research on Medical Education covering medical, dental, nursing and allied health care professional education. The journal covers undergraduate education, postgraduate training and continuing medical education

\section{Dovepress}

including emerging trends and innovative models linking education, research, and health care services. The manuscript management system is completely online and includes a very quick and fair peer-review system. Visit http://www.dovepress.com/testimonials.php to read real quotes from published authors. 